\title{
PENGARUH PENGHARGAAN DAN PEMBERDAYAAN TERHADAP PENGAMBILAN KEPUTUSAN KEPALA SMA SWASTA DI KOTA BEKASI
}

\author{
Irnie Victorynie*
}

\begin{abstract}
The objective of the research is to know the effect of reward and empowerment on decision making on headmaster of private senior high school. This research used quantitative approach. The research was conducted to all of headmaster of private senior high school at Bekasi city by using a survey method with path analysis applied in testing hypothesis. The number of 62 headmasters as sample was selected by using Slovin formula. The research conclude: (1) There is a direct positive effect of reward on decision making. (2) There is a direct positive effect of empowerment on decision making. (3) There is a direct positive effect of reward on empowerment.
\end{abstract}

Keywords: Reward, empowerment and decision making

\section{PENDAHULUAN}

Sekolah menempati posisi penting sebagai suatu institusi yang melaksanakan proses pendidikan pada tataran mikro. Karena di lembaga inilah setiap anggota masyarakat dapat mengikuti proses pendidikan dengan tujuan mempersiapkan mereka dengan berbagai ilmu dan keterampilan agar lebih mampu berperan dalam kehidupan masyarakat. Kedudukan sekolah sangat penting dalam kehidupan masyarakat pada dasarnya tidak terlepas dari fungsi sekolah sebagai lembaga pendidikan bagi masyarakat memiliki peran penting dan menentukan dalam perkembangan masyarakat.

Kepala sekolah sebagai top manajer di sekolah diharapkan dapat memainkan perannya dalam mempengaruhi bawahannya, khususnya para guru dalam meningkatkan kinerja atau prestasi kerjanya. Untuk melaksanakan pekerjaan tersebut tidaklah mudah karena menuntut adanya sejumlah kompetensi yang harus dimiliki oleh kepala sekolah.

Kinerja kepala sekolah merupakan faktor yang signifikan dalam proses pencapaian tujuan-tujuan pendidikan sekolah, sehingga apabila kinerja kepala sekolah baik maka kemajuan sekolah akan tercapai, demikian juga sebaliknya. Sebagai pemimpin pendidikan, Kepala Sekolah dituntut untuk berupaya keras mengelola seluruh kegiatan di sekolah seefektif dan seefisien mungkin agar proses pendidikan di sekolah sesuai dengan yang diharapkan.

Salah satu fungsi kepala sekolah adalah sebagai pengambil keputusan dalam penyelengaraan pendidikan di sekolah. Pengambilan keputusan bukan merupakan suatu kajian sepele yang dapat diabaikan begitu saja, karena apabila pengambilan keputusan mengalami kegagalan, maka masa depan organisasi dipertaruhkan. Oleh karena itu ketepatan dalam pengambilan keputusan menjadi suatu keharusan. Namun demikian untuk mencapai hal tersebut bukanlah hal yang mudah. Diperlukan kecermatan dan ketepatan dalam merumuskan masalah dalam proses pengambilan keputusan. Untuk itu dalam mengambil sebuah keputusan, kepala sekolah harus melakukan berbagai langkah, mulai dari pengindentifikasian masalah, pencarian alternatif penyelesaian masalah, evaluasi daripada alternatif-alternatif tersebut, dan

\footnotetext{
* Staf Pengajar di SMPN 33 Bekasi
} 
pemilihan alternatif keputusan yang terbaik. Kemampuan seorang kepala sekolah dalam membuat keputusan dapat ditingkatkan apabila ia mengetahui dan menguasai teori dan teknik pembuatan keputusan. Dengan peningkatan kemampuan kepala sekolah dalam pembuatan keputusan maka diharapkan dapat meningkatkan kualitas keputusan yang dibuatnya, sehingga akan meningkatkan efisiensi dan efektivitas kerja organisasi.

Namun dalam kenyataannya, tidak semua kepala sekolah dapat dengan mudah mengambil keputusan. Terdapat beberapa faktor yang mempengaruhi terwujudnya sebuah keputusan yang efektif dan sesuai dengan kebutuhan organisasi. Faktor-faktor tersebut antara lain pemberian penghargaan dan pemberdayaan. Kurangnya penghargaan dari atasan baik berupa financial maupun non financial dapat mempengaruhi kepala sekolah dalam melaksanakan tugasnya, termasuk dalam pengambil keputusan bagi organisasi sekolah. Begitu juga dengan pemberdayaan, apabila kepala sekolah tidak menyelenggarakan kegiatan pemberdayaan pada karyawan, maka pengambilan keputusan yang efektif bagi organisasi akan sulit terwujud.

Berdasarkan realita di atas, dalam upaya pencapaian tujuan organisasi, kepala sekolah dituntut untuk mampu mengambil keputusan-keputusan yang efektif dan tepat. Hal ini dapat dilakukan dengan memperhatikan dan meningkatkan dua faktor utama yang telah disebutkan, yakni penghargaan dan pemberdayaan.

Penelitian ini menguji dan menganalisis pengaruh langsung penghargaan dan pemberdayaan terhadap pengambilan keputusan, dengan subjek penelitian adalah kepala sekolah SMA swasta di kota Bekasi.

\section{Pengambilan Keputusan.}

Garry Dessler (2001:98) mendefinisikan pengambilan keputusan sebagai berikut, "decision making is the process of developing and analyzing alternatives and making a choice". Definisi ini mengandung makna bahwa pengambilan keputusan adalah proses mengembangkan dan menganalisis alternatif dan membuat pilihan. Sedangkan menurut Richard L. Daft (2012:238), "decision making is the process of identifying problems and opportunities and then resolving them". Pengambilan keputusan adalah proses dalam mengenali masalah-masalah dan peluang-peluang untuk kemudian dipecahkan.

Adapun menurut Colquitt et. al. (2009:256) mendefinisikan pengambilan keputusan sebagai berikut, "decision making is refering to the process of generating and choosing from a set of alternatives to solve a problem". Pengambilan keputusan adalah mengacu pada proses menghasilkan dan memilih dari satu set alternatif untuk memecahkan masalah

George dan Jones (2012:436) sependapat dengan beberapa pendapat di atas bahwa, "decision making can be defined as the process by which members of an organization choose a specific course of action to respond to the opportunities and problems that confront them". Pengambilan keputusan dapat didefinisikan sebagai proses dimana anggota organisasi memilih aksi tertentu untuk merespon peluang dan masalah yang dihadapi mereka.

Berikut ini penjelasan James L. Gibson et. al. (2006:456) terkait perbedaan tipe keputusan, yaitu sebagai berikut: "1). Programmed Decision. If a particular situation accurs often, a routine procedure usually can be worked out for solving it. Thus, decisions are programmed to the extent that problems are repetitive and routine and a definite procedure has been developed for handling them. 2). Nonprogrammed decision. Decisions are nonprogrammed when they are novel and unstructured. No established procedure exists for handling the problem, 
either because it has not arisen in exactly the same manner before or because it is complex or extremely important. Such problems deserve special treatment". 1). Keputusan yang terprogram adalah jika keputusan yang diambil berdasarkan sering terjadinya suatu situasi yang khusus, maka biasanya akan digunakan prosedur rutin untuk memecahkannya. Dengan demikian, suatu keputusan dapat diprogram sejauh keputusan itu berulang-ulang serta rutin dan telah dikembangkan prosedur yang tertentu untuk menanganinya. 2). Keputusan tidak terprogram jika keputusan tersebut baru dan tidak terstruktur. Belum ada prosedur yang pasti untuk menangani masalah, karena masalah yang timbul tidak persis sama dengan sebelumnya atau karena masalah itu rumit atau sangat penting. Dengan demikian, masalah seperti itu memerlukan penanganan secara khusus.

Langkah-langkah yang harus dilaksanakan dalam pengambilan keputusan menurut Gibson et al. (2006: 459), yaitu: "the decision making process are: (1) Establishing specific goals and objectives and measuring results (2) Identifying problem. (3) Developing alternatives, (4) Evaluating alternatives, (5) Choosing an alternative, (6) Implementing the decision, (7) Controlling and evaluation". Proses pengambilan keputusan adalah: (1) Menetapkan tujuan dan sasaran khusus dan mengukur keberhasilannya (2) Mengidentifikasi masalah. (3) Mengembangkan alternatif, (4) Mengevaluasi alternatif, (5) Memilih alternatif, (6) Melaksanakan keputusan, (7) Mengendalikan dan evaluasi.

Kreitner dan Kinicki (2010:337) menambahkan penjelasan sebagai berikut, "the rational model proposes that managers use a rational four-step sequence when making decisions: (1) identifying the problem, (2) generating alternative solutions, (3) selecting a solution, (4) implementing and evaluating the solution". Model rasional mengusulkan bahwa manajer menggunakan urutan empat-langkah rasional ketika membuat keputusan: (1) mengidentifikasi masalah, (2) menghasilkan solusi alternatif, (3) memilih solusi, (4) melaksanakan dan mengevaluasi solusi.

Berdasarkan deskripsi konsep di atas dapat disintesiskan pengambilan keputusan adalah proses berupa aktivitas seseorang dalam memilih, membangun, menetapkan, dan menghasilkan sebuah pilihan yang akan digunakan untuk menyelesaikan masalah dan memanfaatkan peluang yang ada dengan mendasarkan pada pertimbangan rasional untuk menghasilkan keputusan terbaik, dengan indikator (1) Identifikasi masalah, (2) Membuat solusi alternatif, (3) Memilih solusi, (4) Implementasi solusi, dan (5) Evaluasi solusi.

\section{Penghargaan.}

Hellriegel dan Slocum (2004:96) mendefinisikan, "a reward is an event that a person finds desirable or pleasing". Definisi tersebut mengandung arti bahwa penghargaan adalah suatu peristiwa/perihal dimana seseorang menemukan sesuatu yang diinginkan atau menyenangkan. Sedangkan menurut John Shield (2007:30), "a reward is anything tangible that an organization provides to its employees either intentionally or unintentionally in exchange for the employee's potential or actual work contribution, and to which employees as individuals attach a positive value as a satisfier of certain self defined needs". Penghargaan adalah sesuatu yang nyata yang diberikan oleh organisasi kepada karyawan baik sengaja atau tidak sengaja sebagai bentuk pertukaran atas potensi atau kontribusi kerja karyawan, dan menjadi sesuatu yang bernilai positif bagi karyawan sebagai pemuas kebutuhan tertentu.

Hal senada didefinisikan World at Work (2007:2), "a reward is everything employees get as a result of their employment". Penghargaan adalah segala sesuatu yang karyawan peroleh sebagai hasil dari pekerjaan mereka. Selanjutnya Kreitner dan Kinichi (2010:255) 
menjelaskan bahwa, "rewards are an ever-present and always controversial feature of organizational life". Penghargaan adalah fitur yang selalu ada dan selalu kontroversial dari kehidupan organisasi.

Penghargaan dapat mendorong dan mempengaruhi karyawan dalam organisasi, diantaranya akan berdampak pada tinggi dan rendahnya kinerja karyawan. Hal tersebut dikemukakan oleh Gibson et al. (2006:176), "one of the most powerful influences on individual performance is an organization's reward system". Salah satu pengaruh paling kuat pada kinerja individu adalah sistem penghargaan organisasi.

Penjelasan lain ditambahkan oleh Luthans (2008:93), "organization provide rewards to their personnel in order to motivate their performance and encourage their loyalty and retention". Organisasi memberikan penghargaan kepada personil mereka dalam rangka untuk memotivasi kinerja mereka dan mendorong loyalitas dan retensi mereka.

Berikut ini beberapa tujuan dari pemberian penghargaan dalam organisasi yang dinyatakan oleh Gibson et al. (2006:177), "the main objectives of reward programs are (1) to attact qualified people to join the organization, (2) to keep employees coming to work, and (3) to motivate employees to achieve high levels of performance". Tujuan utama dari program penghargaan adalah (1) untuk menarik orang yang memenuhi syarat untuk bergabung dengan organisasi, (2) untuk menerima karyawan agar datang untuk bekerja, dan (3) untuk memotivasi karyawan untuk mencapai tingkat kinerja yang tinggi.

Penghargaan dalam organisasi terbagi dalam dua kategori, yaitu penghargaan ekstrinsik dan penghargaan intrinsik sebagaimana dijelaskan Gibson et. al. (2006:179) sebagai berikut, "classifies rewards into two broad categories; extrinsic and intrinsic. Extrintic rewards are rewards exsternal to the job, such as pay, promotion, or fringe benefits; Intrinsic rewards are those that are part of the job itself, such as the responsibility, challenge, and feedback characteristics of the job". Mengklasifikasikan penghargaan menjadi dua kategori besar; ekstrinsik dan intrinsik. Penghargaan ekstrinsik adalah penghargaan exsternal dengan pekerjaan, seperti gaji, promosi, atau tunjangan; penghargaan intrinsik adalah mereka yang merupakan bagian dari pekerjaan itu sendiri, seperti tanggung jawab, tantangan, dan karakteristik umpan balik pekerjaan.

Richard L. Daft (2012:466-467) menambahkan, "rewards are of two types: intrinsic and extrinsic. Intrinsic rewards are the satisfactions a person receives in the process of performing a particular action. Extrinsic rewards are given by another person, typically a manager, and include promotions, pay increases, and bonuses". Penghargaan terdiri dari dua jenis: intrinsik dan ekstrinsik. Penghargaan intrinsik adalah kepuasan seseorang yang diterima dalam proses melakukan tindakan. Penghargaan ekstrinsik diberikan oleh orang lain, biasanya manajer, dan termasuk promosi, kenaikan gaji, dan bonus.

Berdasarkan konsep-konsep yang telah dikemukakan di atas, dapat disintesiskan bahwa penghargaan adalah sesuatu yang diberikan atas kontribusi kerja yang telah dilakukan karyawan, yang bertujuan untuk memotivasi karyawan agar berkinerja lebih tinggi, dengan indikator (1) pemberian gaji; (2) pemberian bonus; (3) pemberian tunjangan; (4) Promosi.

\section{Pemberdayaan.}

W. Alan Randolf dalam Kreitner dan Kinicki (2010:445) berpendapat, "empowerment is recognizing and releasing into the organization the power that people already have in their wealth of useful knowledge, experience, and internal motivation". Pemberdayaan adalah mengakui dan menggali kekuatan yang ada pada seseorang untuk kepentingan organisasi yang berupa pengetahuan mereka yang berguna, pengalaman yang berguna, dan motivasi internal yang ada dalam diri meraka. 
Adapun menurut Hellriegel dan Slocum (2004:108), "empowerment means giving employees the authority, skills, and self control to perform their task". Pemberdayaan artinya memberikan karyawan otoritas, keterampilan, dan kontrol diri untuk melakukan tugas mereka. Pendapat senada dikemukakan Gibson et. al. (2006:500), “empowering individuals means granting them permission to utilize their talent, skill, resources, and experience to make decisions to complete their workloads in a timely manner". Pemberdayakan Individu berarti memberikan izin dan peluang bagi karyawan untuk memanfaatkan bakat, keterampilan, sumber daya, dan pengalaman mereka dalam membuat keputusan untuk menyelesaikan beban kerja mereka pada waktu yang tepat.

Selanjutnya Gareth Jones (2010:164) menjelaskan, "empowerment is the process of giving employee at all levels in an organization's hierarchy the authority to make important decisions and to be responsible for their outcomes". Pemberdayaan adalah proses pemberian otoritas kepada karyawan di semua tingkatan dalam hirarki organisasi untuk membuat keputusan penting dan bertanggung jawab atas hasil mereka. Konsep Jones tersebut sejalan dengan pendapatnya Dessler (2001:341), "empowering employees means giving employees the authority, tools, and information they need to do their jobs with greater autonomy, as well as the self-confidence required to perform the jobs effectively". Memberdayakan karyawan artinya memberikan karyawan otoritas, peralatan, dan informasi yang mereka butuhkan untuk melakukan pekerjaan mereka dengan otonomi yang lebih luas, serta rasa percaya diri yang dibutuhkan untuk melakukan pekerjaan secara efektif.

Berdasarkan deskripsi konsep di atas dapat disintesiskan pemberdayaan adalah memberikan peluang bagi karyawan untuk memanfaatkan pengetahuan, keterampilan, dan sumber daya mereka dalam melaksanakan tugas dan pekerjaan untuk kepentingan organisasi, dengan indikator: 1) Pengembangan dan pelatihan, 2) Pelibatan dalam proses pengambilan keputusan, 3) Kewenangan, 4) Kemandirian. 


\section{METODE}

Penelitian ini dilaksanakan pada Sekolah Menengah Atas (SMA) Swasta di Kota Bekasi. Populasi terjangkau dalam penelitian ini berjumlah 74 Kepala SMA Swasta. Sampel diambil dengan menggunakan teknik simple random sampling dengan jumlah 62 kepala SMA Swasta.

Penelitian ini menggunakan metode penelitian survey dengan menggunakan analisis jalur (path analysis) untuk mengetahui adanya pengaruh antar variabel sesuai dengan model kausal yang terbentuk. Sebelum kuesioner digunakan dalam penelitian ini, terlebih dahulu dilakukan ujicoba untuk menentukan validitas dan realibitas instrumen. Hasil tersebut digunakan sebagai instrumen untuk mengambil data dalam penelitian di lapangan.

Analisis data meliputi: 1) deskripsi data; 2) uji prasyarat analisis normalitas; 3) analisis jalur yang meliputi: analisis model, pengujian hipotesis dan penentuan tingkat pengaruh.

\section{HASIL DAN PEMBAHASAN}

Pengaruh Langsung Penghargaan terhadap Pengambilan Keputusan

Berdasarkan hasil perhitungan koefisien jalur sebesar 0,277 dan nilai koefisien korelasi sebesar 0,393. Dengan demikian terdapat pengaruh langsung positif penghargaan terhadap pengambilan keputusan.

Hasil penelitian tersebut sesuai dengan teori yang menunjukkan pengaruh penghargaan terhadap pengambilan keputusan menurut Robbins dan Judge, dalam bukunya berpendapat bahwa, "the organization's reward system influences decision makers by suggesting what choices have better personnel payoff". Teori ini menunjukkan bahwa sistem pemberian penghargaan dalam organisasi mempengaruhi pengambil keputusan dengan menyarankan apa pilihan penghargaan yang lebih baik baik personil.

Hal ini mencerminkan semakin tinggi penghargaan maka semakin tepat pengambilan keputusan.

\section{Pengaruh Langsung Pemberdayaan terhadap Pengambilan Keputusan}

Berdasarkan hasil perhitungan nilai koefisien jalur sebesar 0,349 dan nilai koefisien korelasi sebesar 0,441. Dengan demikian terdapat pengaruh langsung positif pemberdayaan terhadap pengambilan keputusan.

Hasil penelitian tersebut sesuai dengan teori yang menunjukkan pengaruh pemberdayaan terhadap pengambilan keputusan menurut George and Jones, "empowerment often requires managers and supervisors to change the ways they think about decision making". Teori ini menunjukkan bahwa pemberdayaan sering dibutuhkan manajer dan supervisor untuk mengubah cara-cara mereka berpikir tentang membuat keputusan

Sependapat dengan hal tersebut, Robbins dan Coulter menyatakan, "empowerment involves increasing the decision making discretion of worker". Teori ini menjelaskan bahwa pemberdayaan mencakup peningkatan kebijakan pengambilan keputusan dari karyawan

Hal ini mencerminkan semakin meningkat pemberdayaan yang dilaksanakan pada karyawan maka semakin tepat pengambilan keputusan.

\section{Pengaruh Langsung Penghargaan terhadap Pemberdayaan}


Berdasarkan Berdasarkan hasil perhitungan nilai koefisien jalur sebesar 0,334 dan nilai koefien korelasi sebesar 0,334.Dengan demikian terdapat pengaruh langsung positif penghargaan terhadap pemberdayaan.

Hasil penelitian tersebut sesuai dengan teori yang menunjukkan pengaruh penghargaan terhadap pemberdayaan menurut Fred Luthans, "Because intellectual/human capital is now recognized as being central to knowledge management and competitive advantage in the new paradigm environment, attention must be given to rewarding this capital to sustain/retain it and leverage it".

Teori ini menjelaskan bahwa modal intelektual/modal manusia sekarang dikenal sebagai pusat manajemen pengetahuan dan keunggulan kompetitif dalam lingkungan paradigma baru. Perhatian harus diberikan untuk memberikan penghargaan bagi modal ini untuk mempertahankan dan memanfaatkannya. Pendapat Luthans dapat dianalogikan bahwa karyawan sebagai sebuah modal bagi organisasi yang berupa modal intelektual, yang tentunya dapat diberdayakan oleh organisasi. Di samping itu, karyawan harus senantiasa diperlakukan dan diperhatikan dengan baik oleh manajer. Perhatian dan perlakuan yang baik kepada karyawan merupakan bagian dari penghargaan.

Hal senada dikemukakan oleh Gibson dan Ivancevich, "pay systems based on competencies and contribution made, team based incentives, and rewards focusing on improved results are becoming more widely considered and implemented system". Teori ini mengemukakan bahwa sistem pembayaran berbasis pada kompetensi dan kontribusi yang dibuat, insentif berbasis tim, dan penghargaan berfokus pada hasil yang lebih baik menjadi sistem yang lebih luas dipertimbangkan dan dilaksanakan

Hal ini mencerminkan semakin tinggi penghargaan maka semakin meningkat pelaksanaan pemberdayaan.

\section{PENUTUP}

Kesimpulan. Berdasarkan hasil penelitian ini dapat disimpulkan bahwa:

1. Terdapat pengaruh positif penghargaan terhadap pengambilan keputusan yang ditentukan oleh derajat besarnya pengaruh dalam bentuk koefisien korelasi dan koefisien jalur. Nilai koefisien jalur menentukan besaran varians pengambilan keputusan ditentukan oleh penghargaan. Selanjutnya dapat diketahui signifikansi pengaruh antara penghargaan terhadap pengambilan keputusan secara parsial. Hal ini memiliki makna dan penegasan bahwa penghargaan secara empiris bukan satusatunya variabel prediktor bagi varians skor pengambilan keputusan.

2. Terdapat pengaruh positif pemberdayaan terhadap pengambilan keputusan yang ditentukan oleh derajat besarnya pengaruh dalam bentuk koefisien korelasi dan koefisien jalur. Nilai koefisien jalur menentukan besaran varians pengambilan keputusan ditentukan oleh pemberdayaan. Selanjutnya dapat diketahui signifikansi pengaruh antara pemberdayaan terhadap pengambilan keputusan secara parsial. Hal ini memiliki makna dan penegasan bahwa pemberdayaan secara empiris bukan satu-satunya variabel prediktor bagi varians skor pengambilan keputusan.

3. Terdapat pengaruh positif penghargaan terhadap pemberdayaan yang ditentukan oleh derajat besarnya pengaruh dalam bentuk koefisien korelasi dan koefisien jalur. Nilai koefisien jalur menentukan besaran varians pemberdayaan ditentukan oleh penghargaan. Selanjutnya dapat diketahui signifikansi pengaruh antara penghargaan terhadap pemberdayaan secara parsial. Hal ini memiliki makna dan penegasan bahwa penghargaan secara empiris bukan satu-satunya variabel prediktor bagi varians skor pemberdayaan. 
Saran. Beberapa hal yang disarankan dalam penelitian ini adalah sebagai berikut:

1. Bagi yayasan, agar lebih memperhatikan kebutuhan kepala sekolah, baik menyangkut kebutuhan penghargaan bagi kepala sekolah itu sendiri, maupun kebutuhan pemberdayaan kepala sekolah bagi kepentingan organisasi sekolah,

2. Bagi kepala sekolah, agar dapat mengembangkan kompetensi dan wawasan, terutama yang berkaitan dengan cara pengambilan keputusan dalam mengelola organisasi sekolah, sehingga keputusan-keputusan yang diambil senantiasa tepat dan sesuai dengan kebutuhan organisasi sekolah,

3. Bagi peneliti lain, agar dapat dijadikan bahan rujukan dalam rangka penelitian lanjutan terkait dengan pengambilan keputusan 


\section{DAFTAR RUJUKAN}

Colquitt, LePine, dan Wesson. Organizational Behavior: Improving Performance and Commitment in the Workplace. New York: McGraw-Hill Companies, Inc, 2009

Daft, Richard L. New Era of Management. South-Western: Cengage Learning, 2012

Dessler, Gary. Management leading people and organizations in the 21 st century. New Jersey: Prentice Hall, Inc, 2001

George, Jennifer M. and Gareth R. Jones. Understanding and Managing Organizational Behavior. New Jersey: Pearson Education, Inc, 2012

Gibson, James L. et al. Organizations: Behavior, Structure, Processes. New York: McGrawHill Companies, Inc, 2006

Hellriegel, Don dan John W. Slocum. Organizational Behavior. Canada: South - Western, a Division of Thomson Learning, 2004

Jones, Gareth. Organizational Theory: Design and Change. New Jersey: Pearson Education, Inc, 2010

Kreither, Robert dan Angelo kinicki. Organizational Behavior. New York: McGraw-Hill Companies, Inc, 2010

Shield, John. Managing Employee Performance and Reward: Concepts, Practices, Strategies. Australia: Cambridge University Press, 2007

World at Work. The World at Work Handbook of Compensation, Benefits, and Total Rewards. New Jersey: John Wiley and Sons, Inc, 2007 